Structural Eng. / Earthquake Eng. Vol.6. No.1, 123s-130s. April 1989

Japan Society of Civil Engineers (Proc. of JSCE No.404/I-11)

\title{
DAMPING CHARACTERISTICS OF CABLE-STAYED BRIDGES ASSOCIATED WITH ENERGY DISSIPATION
} AT MOVABLE SUPPORTS

\author{
By Kazuhiko KAWASHIMA* and Shigeki UNJOH**
}

\begin{abstract}
Damping characteristics are one of the most significant factors for seismic design of cable-stayed bridges. Among various sources of energy dissipation which results in damping of cable-stayed bridges, an effect of energy dissipation at movable supports is studied in this paper, because it can be considered one of the major factors affecting damping characteristics of cable-stayed bridge in longitudinal vibration.

Three cable-stayed bridges are idealized by discrete analytical models in which friction force developed at movable supports is modeled by the Coulomb friction. Damping characteristics are determined by computed decay of free oscillation developed by smooth release from the original deformation specified.

It is found from the analyses that damping ratio of cable-stayed bridges associated with energy dissipation at movable supports depends on mode shapes. Therefore, damping characteristics of cable-stayed bridge should be carefully evaluated considering mode shape.

Keywords : damping ratio, cable-stayed bridge, dynamic response analysis, Coulomb friction 'force
\end{abstract}

\section{INTRODUCTION}

Although cable-stayed bridges have been constructed at various countries, little is known about the seismic behavior subjected to significant earthquake ground motions ${ }^{1) .22}$. Special interests are extended to damping characteristics of cable-stayed bridges. It is general in seismic design to assume a damping ratio of approximately $2-5 \%$ of critical for superstructure, while damping ratio estimated from field observation such as forced vibration tests is generally much smaller than these values ${ }^{3) \sim 7)}$. Such discrepancies of damping ratio between observed in field tests and assumed in seismic design have generally been regarded as an effect of amplitude of oscillation, i. e., amplitude developed during forced vibration tests is generally much smaller than that developed during severe earthquake ground motions. It has been recognized that vibration with larger amplitude may result in larger damping. However, few investigations have been made for such assumptions on damping characteristics of cable-stayed bridges.

Damping of cable-stayed bridges may be developed by various factors such as hysteretic damping of materials, energy dissipation at movable supports, radiational damping at foundation, etc. Because energy dissipation at movable supports can be considered one of the major factors affecting damping characteristics of cable-stayed bridges, the effect of energy dissipation at movable supports is investigated in this study. For isolating such effect from other factors, it is assumed that the energy dissipation occurs only at movable supports, i. e., the structures including girders, towers and cables are assumed as elastic with no energy dissipation.

* Member of JSCE, Dr. Engr., Head of Earthquake Engineering Division, Earthquake Disaster Prevention Department, Public Works Research Institute, Ministry of Construction (Tsukuba Science City, Ibaraki-ken, Japan)

** Member of JSCE, Research Engineer, Earthquake Engineering Division, ditto. 


\section{ENERGY DISSIPATION AT MOVABLE SUPPORTS}

Cable-stayed bridges are generally supported by piers and/or abutments through several bearing supports. For reducing internal force caused by temperature change and live load, relative movements between girders and piers are generally released in longitudinal direction with use of movable supports. At such movable supports, relative movements between girders and piers are developed when the cable-stayed bridge is subjected to significant earthquake ground motions. It should be noted here that the relative movements are developed only at movable supports in accordance with seismic response in longitudinal direction. Friction forces associated with relative displacement between superstructure and substructure result in energy dissipation.

Friction force developed at movable supports is idealized by the Coulomb friction force. Although actual friction force developed at movable supports may have complex characteristics such as difference between static and dynamic friction coefficient, amplitude dependence of friction coefficient, etc., they are disregarded in this study for simplicity. Friction force is a self-equilibrium force which acts on a contact plane of bearing supports in proportion to the contact force. Direction of the force developed when the relative movement at the contact plane occurs is opposite, as shown in Fig. 1, to the direction of relative velocity developed at the contact plane, i. e., the friction force $F_{r}^{I}$ and $F_{r}^{J}$ acting on points $I$ and $J$, respectively, may be expressed as $^{8)}$

$$
\left.\begin{array}{ll}
F_{r}^{I}=-F_{r}^{J}=\mu N \operatorname{sign}(\dot{r}) & \dot{r} \neq 0 \\
-\mu N<F_{r}^{I}=-F_{r}^{J}<\mu N & \dot{r}=0
\end{array}\right\}
$$

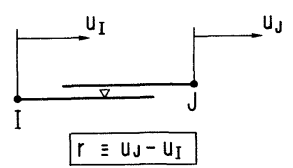

(a) Definition of Coordinate System

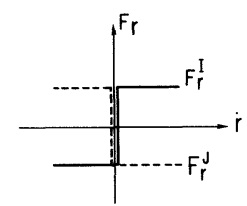

(b) Force vs. Relative Velocity

Fig. 1 Coulomb Friction Force.

in which $\mu$ and $N$ represent coefficient of Coulomb friction and contact force, respectively, and $\dot{r}$ represents relative velocity between $I$ and $J$.

For determining damping characteristics of cable-stayed bridge associated with friction force developed at movable supports, the cable-stayed bridges is laterally pulled in longitudinal direction in accordance with a mode shape considered, and then released smoothly with zero initial velocity to result in a free vibration. Damping characteristics can be obtained from a decay of free oscillation as

$$
\delta=\frac{2 \pi h}{\sqrt{1-h^{2}}}=\log _{e} \frac{a_{m}}{a_{m+1}} \text {. }
$$

in which $\delta$ and $h$ represent logarithmic damping ratio and damping ratio of critical, respectively, and $a_{m}$ and $a_{m+1}$ represent amplitude of free vibration at $m$-th and $(m+1)$-th oscillation, respectively. It should be noted here that in addition to initial displacements, initial accelerations which were determined by multiplying the initial displacement by square of the angular natural frequency of the mode specified were also considered as an initial condition of the free vibration.

For calculating the free oscillation subjected to friction force at movable supports, a cable-stayed bridge was modeled by a discrete analytical model in which movable supports were idealized by a nonlinear restoring force vs. relative velocity model represented by Eq. (1). No damping forces excluding the friction force at movable supports were considered in the analysis to isolate the effect of friction. The equation of motions including friction force may be formulated in an incremental form, and can be solved for each time increment according to the standard dynamic analysis procedure ${ }^{10,11)}$. Iteration to approve equilibrium of equations of motion was made when it was necessary. A computer program NON-BRIDGE developed at the Public Works Research Institute was used for the nonlinear dynamic response analyses. 


\section{CABLE-STAYED BRIDGES STUDIED}

Effects of energy dissipation at movable supports were studied for two cable-stayed bridges as shown in Fig. 2. The two span continuous cable-stayed bridge, which is designated hereinafter as A1-bridge, has a deck length of $380 \mathrm{~m}$ with single tower. Fourteen cables are placed symmetrically in a form of "fan". The girder is rigidly connected with tower, with two ends being supported by movable supports. The weight of girder, tower and cables is $4435 \mathrm{tf}, 734 \mathrm{tf}$ and $120 \mathrm{tf}$, respectively. Reaction force at the both end supports due to dead weight of the superstructure is $563 \mathrm{tf}$, which is regarded as the contact force $N$ defined by Eq. (1). Although contact force varies in time due to mode coupling with vertical motion, such a change of contact force is disregarded in this analysis for simplicity. The three span continuous cable-stayed bridge, which is designated here as B-bridge, has a deck length of $755 \mathrm{~m}$ with symmetrical distribution of mass and stiffness. The girder is connected with two towers by cable restrainers for aiming to reduce seismic effects. The girders are supported by cables and

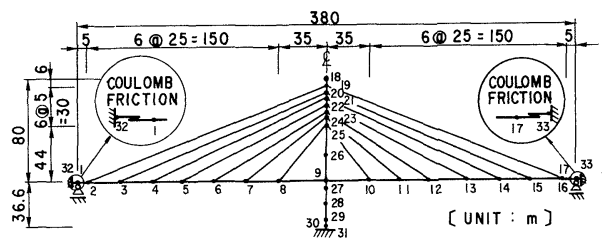

(a) Two Span Continuous ('able-Stayed Bridge (Al and $\Lambda 2-B r i d g e)$ two end movable supports. The weight of girder, tower and cables is $9630 \mathrm{tf}, 1734 \mathrm{tf}$ and $604 \mathrm{tf}$, respectively. The reaction force at the two end supports due to dead weight of the superstructure is $203 \mathrm{tf}$. It should be noted here that soilfoundation interaction is disregarded in this study for simplicity. The bottom of towers is assumed rigidly supported by ground for both cablestayed bridges.

Table 1 shows natural period, mode participation factor and effective mass for the lowest ten modes, which were computed by disregarding friction force at movable supports. The results for A2-bridge, which will be described later, are also included in Table 1. It is apparent from Table 1, that the predominant mode of the superstructure in longitudinal direction is 5 th and 6th modes in A1-bridge and 3rd mode in B-bridge.

Figs. 3(a) and (b) represent 5th and 6th mode shapes of A1-bridge, which is the first and second predominant modes in longitudinal

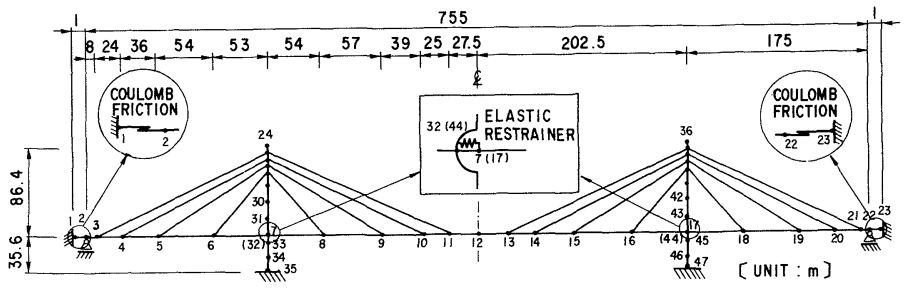

(b) Three Span Continuous (able-Stayed Bridge (B-Bridge)

Fig. 2 Cable-Stayed Bridges Studied and Analytical Idealization.

Table 1 Natural Period, Mode Participation Factor and Effective Mass. (a) Two Span Continuous Cable-S tayed Bridge (A-Bridge)

\begin{tabular}{|c|c|c|c|c|c|c|}
\hline \multirow{2}{*}{ Model } & \multirow{2}{*}{ Mode } & \multirow{2}{*}{$\begin{array}{l}\text { Natural } \\
\text { Period } \\
\text { [sec] }\end{array}$} & \multicolumn{2}{|c|}{ Mode Participation Factor } & \multicolumn{2}{|c|}{ Effective Mass[ $\mathrm{tf} \cdot \mathrm{m} / \mathrm{sec}^{2}$ ] } \\
\hline & & & Long i tud inal & Vertical & Long i tud inal & Vertical \\
\hline \multirow{10}{*}{$\begin{array}{l}\mathrm{A} 1 \text { - } \\
\text { Bridge }\end{array}$} & 1 & 2.87 & -1.9 & -0.0 & 4 & 0 \\
\hline & 2 & 1.26 & -0.0 & 20.8 & 0. & 433. \\
\hline & 3 & 0.91 & -2.1 & -0.0 & 4. & 0. \\
\hline & 4 & 0.71 & 0.0 & 7.3 & 0 & 53. \\
\hline & 5 & 0.52 & 23.7 & 0.0 & 563. & 0. \\
\hline & 6 & 0.48 & 14.3 & 0.0 & 204. & 0. \\
\hline & 7 & 0.44 & 0.0 & 9.4 & 0. & 88 \\
\hline & 8 & 0.31 & -0.2 & -0.0 & 0 . & 0 \\
\hline & 9 & 0.28 & -0.0 & 1.4 & 0. & 2. \\
\hline & 10 & 0.25 & 2.2 & -0.0 & 5. & 0. \\
\hline \multirow{10}{*}{$\begin{array}{l}\mathrm{A} 2- \\
\mathrm{Br} \text { idge }\end{array}$} & 1 & 2.87 & -1.9 & -0.0 & 4. & 0 \\
\hline & 2 & 1.26 & -0.0 & 20.8 & 0. & 433. \\
\hline & 3 & 0.91 & 3.2 & 0.0 & 10. & 0. \\
\hline & 4 & 0.71 & 0.0 & 7.3 & 0. & 53. \\
\hline & 5 & 0.67 & -27.7 & -0.0 & 767. & 0. \\
\hline & 6 & 0.49 & 1.9 & -0.0 & 4. & 0. \\
\hline & 7 & 0.44 & -0.0 & 9.4 & 0. & 88. \\
\hline & 8 & 0.31 & -0.1 & -0.0 & 0. & 0. \\
\hline & 9 & 0.28 & -0.0 & 1.4 & 0. & 2. \\
\hline & 10 & 0.25 & -1.1 & 0.0 & 1. & 0. \\
\hline
\end{tabular}

\begin{tabular}{|c|c|c|c|c|c|}
\hline \multirow{2}{*}{ Mode } & \multirow{2}{*}{$\begin{array}{l}\text { Natural } \\
\text { Period } \\
{[\text { sec] }}\end{array}$} & \multicolumn{2}{|c|}{ Mode Participation Factor } & \multicolumn{2}{|c|}{ Effective Mass [ $\left.\mathrm{t} f \cdot \mathrm{m} / \mathrm{sec}^{2}\right]$} \\
\hline & & Longitudinal & Vertical & Longitudinal & Vertical \\
\hline 1 & 4.61 & 0.0 & 10.2 & 0 & 103. \\
\hline 2 & 3.21 & -8.8 & 0.0 & 77. & 0 \\
\hline 3 & 2.11 & $\begin{array}{ll}31.4 \\
\end{array}$ & 0.0 & 983. & 0 \\
\hline 4 & 1.93 & -0.0 & 17.0 & 0 & 288 \\
\hline 5 & 1.73 & 2.7 & 0.0 & 7. & 0 \\
\hline 6 & 1.47 & 0.0 & 15.5 & 0. & 239. \\
\hline 7 & 1.11 & -0.6 & 0.0 & 0. & 0 \\
\hline 8 & 0.97 & -0.0 & 0.3 & 0. & 0. \\
\hline 9 & 0.90 & 0.2 & -0.0 & 0. & 0. \\
\hline 10 & 0.84 & -0.0 & 8.0 & 0. & 64. \\
\hline
\end{tabular}


direction, respectively, with natural period of $0.52 \mathrm{sec}$ ( 5 th mode) and $0.48 \mathrm{sec}$ (6th mode). Because A1bridge has two predominant modes with close natural period in longitudinal direction, mode coupling between two modes occurs as will be discussed in the following section. Therefore, another cable-stayed bridge which has arbitrarily $50 \%$ lower stiffness only at the tower-pier as compared with the original bridge (A1-bridge) was decided to be analyzed for comparison. This bridge, designated hereinafter as A2-bridge, has a predominant mode with natural period of $0.67 \mathrm{sec}$ as shown in Table 1 .

Fig. 3(c) represents 5 th mode shape of A2-bridge. It should be noted that A2-bridge has only one predominant mode in longitudinal direction and that the vertical amplitude associated with unit longitudinal motion is much smaller in A2-bridge than in A1-bridge.

On the other hand, Fig. $3(\mathrm{~d})$ shows 3rd mode shape of B-bridge, which is the most predominant mode in longitudinal direction with natural period of $2.11 \mathrm{sec}$. Other predominant modes in longitudinal direction having the close natural period with $2.11 \mathrm{sec}$ do not ex-

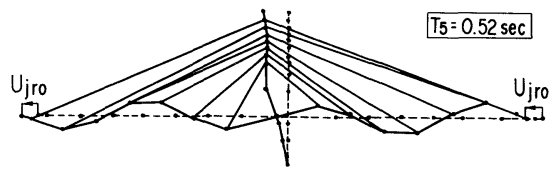

(a) 5th Mode of A1-Bridge

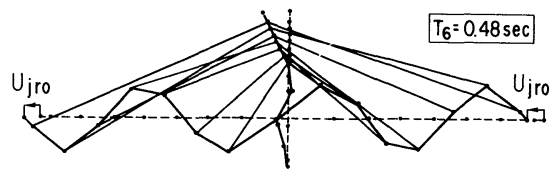

(b) 6th Mode of A1-Bridge

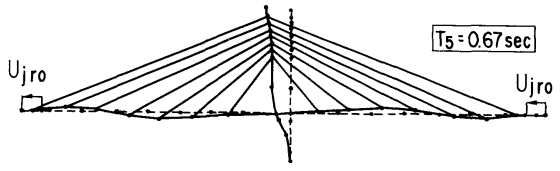

(c) 5th Mode of A2-Bridge

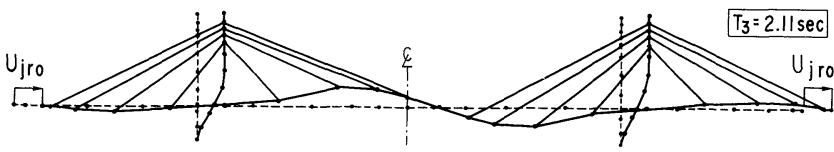

(d) 3rd Mode of B-Bridge

Fig. 3 Predominant Modes in Longitudinal Direction.

Table 2 Case of Analysis

\begin{tabular}{|c|c|c|c|c|}
\hline Case & Model & $\begin{array}{c}\text { Natural Mode } \\
\text { Specified }\end{array}$ & $\begin{array}{l}\text { Natural } \\
\text { Period } \\
\text { [sec] }\end{array}$ & $\begin{array}{l}\text { Coefficient } \\
\text { of Friction } \mu\end{array}$ \\
\hline 1 & \multirow{4}{*}{ A1-Bridge } & \multirow{2}{*}{5 th } & \multirow{2}{*}{0.52} & 0.1 \\
\hline 2 & & & & 0.2 \\
\hline 3 & & \multirow{2}{*}{6 th } & \multirow{2}{*}{0.48} & 0.1 \\
\hline 4 & & & & 0.2 \\
\hline 5 & \multirow{2}{*}{ A2-Bridge } & \multirow{2}{*}{5 th } & \multirow{2}{*}{0.67} & 0.1 \\
\hline 6 & & & & 0.2 \\
\hline 7 & \multirow{2}{*}{ B-Bridge } & \multirow{2}{*}{$3 \mathrm{rd}$} & \multirow{2}{*}{2.11} & 0.1 \\
\hline 8 & & & & 0.2 \\
\hline
\end{tabular}
ist.

For the three models, coefficient of friction $\mu$ defined by Eq. (1) at the end movable supports is assumed as 0.1 and 0.2 . Thus, eight cases are totally analyzed as shown in Table 2. The initial lateral displacement of the girder at both ends is assumed as $30 \mathrm{~cm}$ in all the eight cases.

\section{EFFECT OF ENERGY DISSIPATION AT MOVABLE SUPPORTS}

Fig. 4 shows decay of free oscillation at the end of girder and modal damping ratio $h$ of critical determined by Eq. (2). Although the free oscillation seems to decay almost linearly with time, there are some variation from such linear decay. Therefore, the damping ratio $h$ directly determined by Eq. (2) based on amplitude of successive peaks shows variation in time. This is particularly significant for 5 th and 6 th modes of A 1-bridge. Therefore, damping ratio $h$ was also determined based on a linear approximation of the successive peaks of free oscillation as

$$
k=\frac{\sum a_{m} t_{m}-\left(\sum a_{m} \sum t_{m}\right) / n}{\sum t_{m}^{2}-\left(\sum t_{m}\right)^{2} / n}
$$

in which $k, t_{m}$, and $n$ represent the gradient of line least-square-fitted to the peak of free oscillation, time when successive peak $a_{m}$ occurs, and number of peaks considered, respectively. From the gradient $k$ of the free oscillation, amplitude $a_{m+1}$ can be estimated as 
$a_{m+1}=a_{m}-T k$

in which $T$ represents the natural period of the free oscillation. Substituting Eq. (4) into Eq. (2), one can determine the damping ratio. The damping ratio $h$ thus determined is also presented in Fig. 4 . These results agree well with the general trends of the damping ratio determined by Eq. (2).

It is interesting to note in Fig. 4 that the variation of damping ratio determined by Eq. (2) is considerably large for 5 th and 6 th modes of A1-bridge than for other cases, i. e., A2-bridge and B-bridge. Because both modes have the close natural periods, such variation of the damping ratio may be attributed to a combination of 5 th and 6 th modes, i. e., although initial displacements and accelerations were specified in accordance with mode shape of either 5 th mode or 6 th mode, composition of two modes has likely developed due to mode coupling between 5 th and 6 th modes. This results in variation of the damping ratio $h$ determined by Eq. (2).

Fig. 5 shows damping ratio vs. displacement amplitude relation determined from Fig. 4. Damping ratio

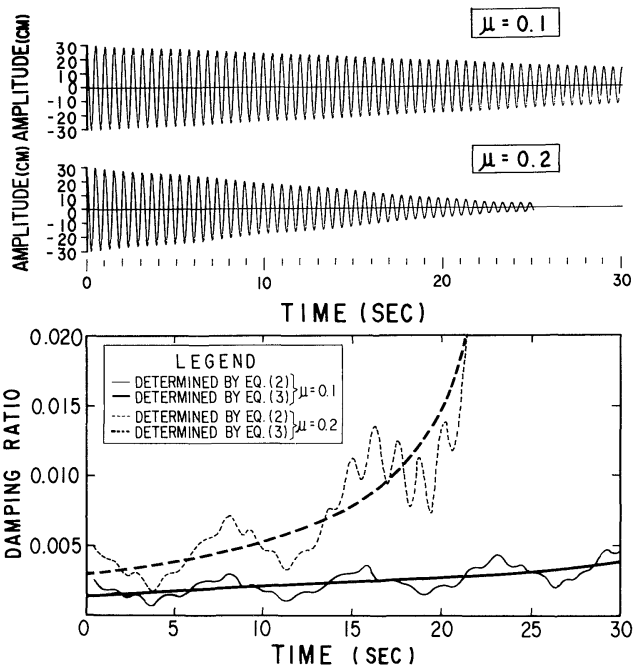

(a) $5 \mathrm{th}$ Mode of A l-Bridge
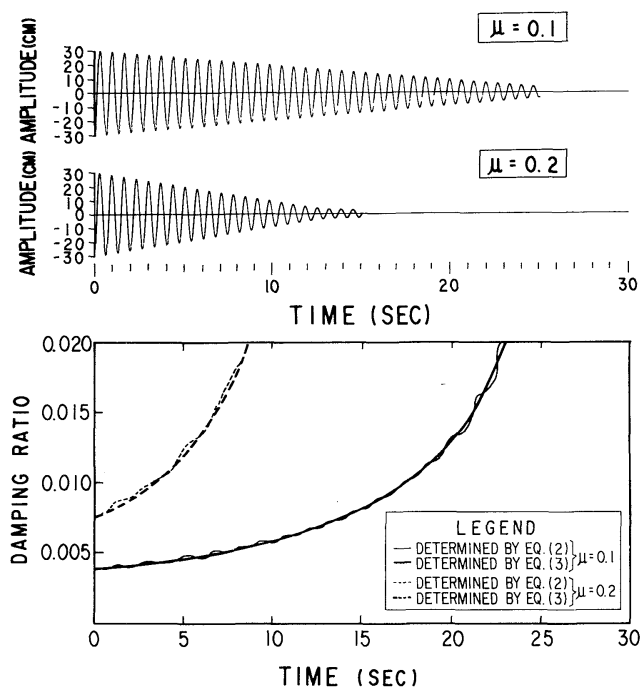

(c) $5 \mathrm{th}$ Mode of $\mathrm{A} 2-\mathrm{Br}$ idge
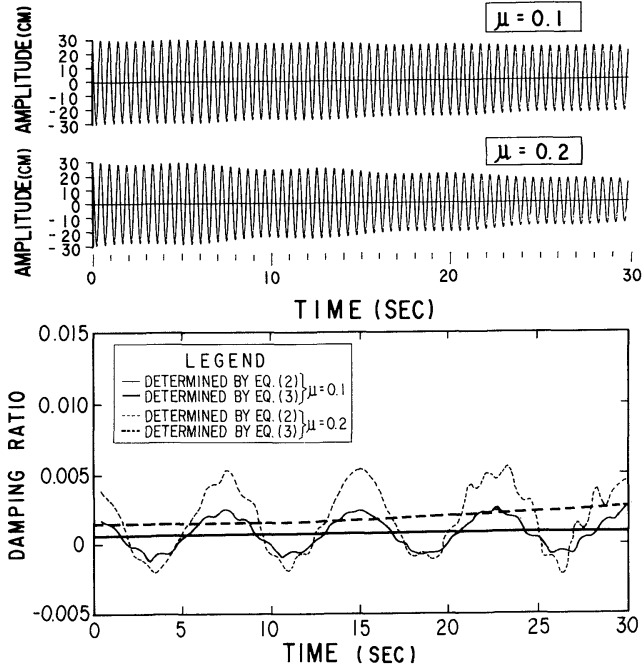

(b) $6 \mathrm{th}$ Mode of $\mathrm{Al}-\mathrm{Bridge}$
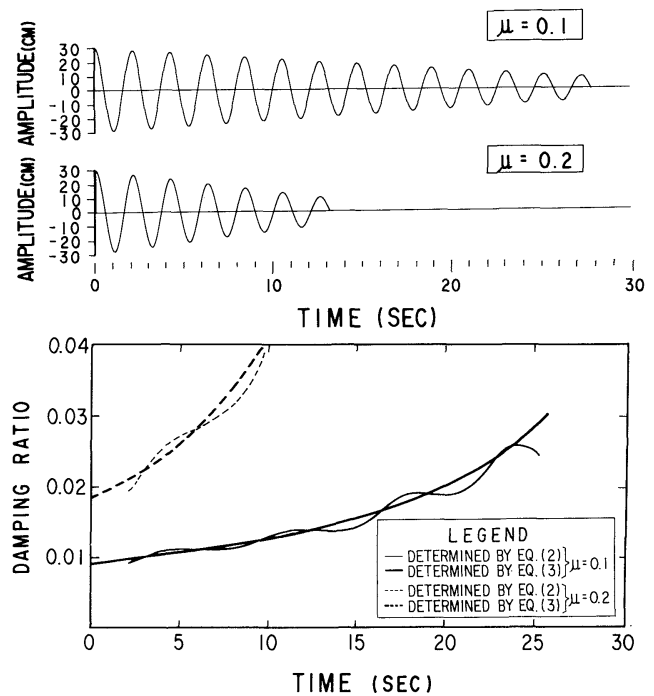

(d) 3 rd Mode of $\mathrm{B}-\mathrm{Bridge}$

Fig. 4 Decay of Free Oscillation and Damping Ratio. 


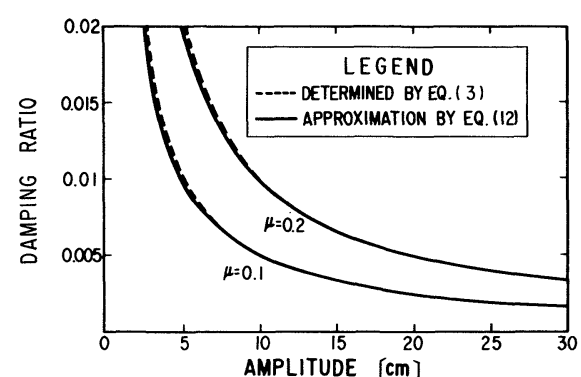

(a) 5 th Mode of Al-Bridge

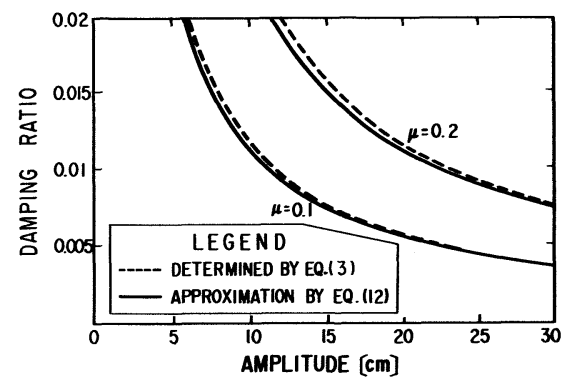

(c) 5 th Mode of A2-Bridge

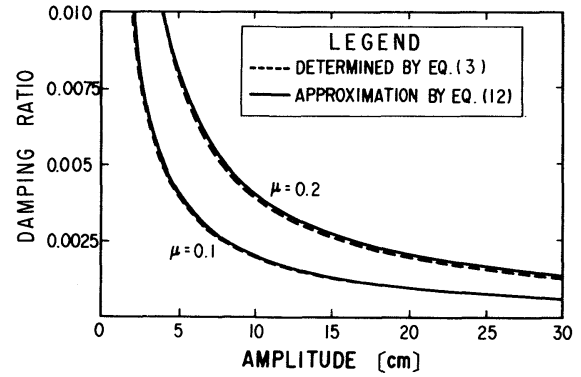

(b) 6 th Mode of A1-Bridge

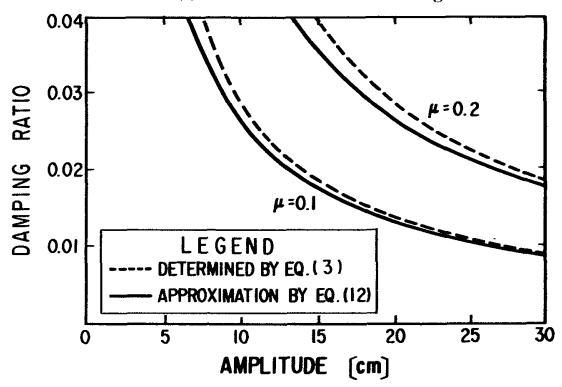

(d) 3 rd Mode of $\mathrm{B}$-Bridge

Fig. 5 Damping Ratio vs. Amplitude of Free Oscillation Relation.

Table 3 Damping Ratio Caused by Friction Force at Movable Supports.

\begin{tabular}{|c|c|c|c|c|c|}
\hline \multirow{2}{*}{ Model } & \multirow{2}{*}{$\begin{array}{c}\text { Natural Mode } \\
\text { Specified }\end{array}$} & $\begin{array}{c}\text { Friction } \\
\text { Coefficient }\end{array}$ & \multicolumn{3}{|c|}{ Relative Displacement at Movable Support } \\
\cline { 3 - 6 } & \multirow{3}{*}{$\begin{array}{c}\text { A } 1- \\
\text { Bridge }\end{array}$} & 0.1 & 0.0016 & 0.0024 & 0.0049 \\
\cline { 3 - 6 } & \multirow{2}{*}{$6 \mathrm{th}$} & 0.2 & 0.0032 & 0.0049 & 0.0099 \\
\cline { 3 - 6 } & \multirow{2}{*}{$5 \mathrm{th}$} & 0.1 & 0.0007 & 0.0010 & 0.0020 \\
\hline \multirow{2}{*}{$\begin{array}{c}\text { A 2- } \\
\text { Bridge }\end{array}$} & \multirow{2}{*}{$3 \mathrm{rd}$} & 0.1 & 0.0038 & 0.0057 & 0.0117 \\
\hline B- & 0.1 & 0.0077 & 0.0117 & 0.0242 \\
\hline Bridge & 3 & 0.2 & 0.0186 & 0.0288 & 0.0640 \\
\hline
\end{tabular}

determined by Eq. (3) is presented here. Predicted damping ratio, which will be described in the following section, is also included in Fig. 5. Of particular importance is the amplitude dependence of damping ratio, i. e., damping ratio increases as the amplitude of free oscillation decreases. It should be noted that such a tendency is opposite to that which has been considered for damping characteristics of cable-stayed bridges. It should be also noted that although the damping ratio tends to increase in accordance with decrease of amplitude, it has a certain limit because the free oscillation terminates at the time when force developed at movable support becomes less than the friction force.

It is interesting to note that the damping ratio $h$ varies in accordance with mode. For example, the damping ratio of $\mathrm{A} 1$-bridge is larger in 5 th mode than 6 th mode. The damping rato increases linearly with an increases of coefficient of friction $\mu$.

Table 3 summalizes the damping ratio thus obtained from longitudinal free oscillation for the three cable-stayed bridges. In case of coefficient of friction $\mu$ of 0.1 , damping ratio takes a value ranging from 0.0007 (6th mode) to 0.0016 ( 5 th mode) for A1-bridge, 0.0038 for A2-bridge and 0.0092 for B-bridge for displacement amplitude of $30 \mathrm{~cm}$. These values increase in accordance with decrease of displacement amplitude and increase of coefficient of friction.

\section{ESTIMATION OF DAMPING RATIO FROM MODE SHAPE}

Energy dissipation $\Delta E_{j}^{m}$ associated with friction force during one cycle of the $j$-th mode between a time 
interval from $t_{m}$ to $t_{m}+T_{j}$ may be obtained as

$$
\Delta E_{j}^{m}=\int_{t_{m}}^{t_{m}+T_{j}}\left|F_{r}\right| d r
$$

in which $T_{j}$ and $F_{r}$ represent natural period of $j$-th mode and friction force defined by Eq. (1), respectively, and $r$ represents relative desplacement between upper and lower contact planes of movable supports. Because the movable supports at both ends of girder are assumed to be supported by rigid substructures, displacement of the girder at each end directly represents the relative displacement between the girder and the pier at the corresponding movable support. Therefore, the energy dissipation $\Delta E_{j}^{m}$ at the movable supports during one cycle may be written as

$$
\Delta E_{j}^{m}=4 \sum_{r} F_{r} \cdot u_{j r}^{m}
$$

were $u_{j r}^{m}$ represents the displacement at nodal point $r$ in accordance with $j$-th mode at the time $t_{m}$. On the other hand, kinematic energy of the bridge $E_{j}^{m}$ corresponding to $j$-th mode can be obtained as

$$
E_{j}^{m}=\frac{1}{2} \omega_{j}^{2} \sum_{i} m_{i}\left(u_{j i}^{m}\right)^{2}
$$

where $\omega_{j}$ and $m_{i}$ represent angular natural frequency of $j$-th mode and lumped mass at nodal point $i$, respectively. Introducing a coefficient $\Gamma_{j}^{m}$ defined as

$$
u_{j i}^{m}=\Gamma_{j}^{m} \cdot \phi_{j i}
$$

in which $\psi_{j i}$ represents amplitude of $j$-th natural mode at nodal point $i$, and substituting Eq. (8) into Eqs. (6) and (7), one obtains

$$
\begin{aligned}
& \Delta E_{j}^{m}=4 \Gamma_{j}^{m} \cdot \sum_{r} F_{r} \cdot \psi_{j r} \\
& E_{j}^{m}=\frac{1}{2} \omega_{j}^{2}\left(\Gamma_{j}^{m}\right)^{2} M_{j} \cdots \cdots
\end{aligned}
$$

in which $M_{j}$ represents a generalized mass of $j$-th mode defined as

$$
M_{j}=\sum_{i} m_{i}\left(\phi_{j i}\right)^{2}
$$

Therefore, through analogy of one-degree-of-freedom system, an equivalent damping ratio $h_{j}$ may be obtained for $j$-th mode as

$$
h_{j}=\frac{1}{4 \pi} \frac{\Delta E_{j}^{m}}{E_{j}^{m}}
$$

Substituting Eqs. (9) and (10) into Eq. (12), one obtains

$$
h_{j}=\frac{2}{\pi \cdot \omega_{j}^{2} \cdot \Gamma_{j}^{m} \cdot M_{j}} \sum_{r} F_{r} \cdot \psi_{j r}
$$

It should be noted here that during free oscillation $\Gamma_{j}^{m}$ decreases almost linearly with time as shown in Fig. 4, which, in turn, results in an increase of damping ratio $h$ in accordance with time increase. This is the reason why the increase of damping ratio in accordance with the decrease of amplitude takes place during the free oscillation.

Predicted damping ratio vs. displacement amplitude (at end of girder) relation determined by Eq. (13) is presented in Fig. 5 in comparison with that obtained by nonlinear time response analyses. Good agreement is observed between the two. Therefore, Eq. (13) may be used to evaluate damping ratio of a cable-stayed bridge subjected to friction force at movable supports.

\section{CONCLUSIONS}

For aiming to study damping characteristics of cable-stayed bridges, damping ratio associated with longitudinal free oscillation subjected to friction force at movable supports was investigated with use of nonlinear dynamic response analyses for three cable-stayed bridges. An analytical procedure is also proposed to evaluate damping ratio from mode shape of cable-stayed bridge. From the analyses presented herein, the following conclusions may be deduced : 
(1) Energy dissipation associated with friction force at movable supports brings an increase of damping ratio of the bridge in accordance with decrease of amplitude of free oscillation.

(2) Damping ratio varies in accordance with mode shape. Therefore, damping characteristics of cable-stayed bridges should be determined carefully based on mode shape.

(3) Damping ratio associated with energy dissipation at movable supports increases linearly with increasing coefficient of friction at the movable supports.

(4) Damping ratio associated with the most predominant mode in longitudinal oscillation is from 0.0007 to 0.0016 for A1-bridge, 0.0038 for A2-bridge and 0.0092 for B-bridge for displacement amplitude of $30 \mathrm{~cm}$.

(5) Damping ratio predicted by Eq. (13) based on mode shape agrees well with that obtained by nonlinear dynamic response analyses, and hence, the proposed simplified Eq. (13) may be used for evaluating the damping ratio of cable-stayed bridges subjected to friction at movable supports.

\section{ACKNOWLEDGEMENT}

The authors would like to express their sincere appreciation to Mr. Akihide Kubo, former visiting researcher at Public Works Research Institute from P. S. Concrete Co. Ltd, for his effort in performing nonlinear dynamic response analyses. Special thanks are also extended to Dr. Nobuyuki Narita, Vice Director of PWRI, and Dr. Toshio Iwasaki, Director of Planning Department of PWRI, for their encouragement throughout this study.

\section{REFERENCES}

1) Kawashima, K., Unjoh, S. and Azuta, Y. : Seismic Design Procedure of Cable-Stayed Bridges, Part 1, Dynamic Characteristics of Cable-Stayed Bridges from Field Vibration Test Results, Vol. 2388, Technical Memorandum of PWRI, 1986.

2) Tada, H. : The Trends of Construction Technique of Cable-Stayed Bridges, Vol. 2292, Technical Memorandum of PWRI, 1986.

3) Itoh, M. and Katayama, T. : Damping of Bridge Structures, Proc. of Japan Society of Civil Engineers, Vol.177, 1965.

4) Itoh, M. : Damping Characteristics of Bridge Superstructures, KABSE, Vol. 1, 1986.

5) Kato, M. and Shimada, S. : Statistical Analysis on the Measured Bridge Vibration Data, Proc. of Japan Society of Civil Engineers, Vol.311, 1981.

6) Kuribayashi, E. and Iwasaki, T. : Dynamic Properties of Highway Bridges, 5th WCEE, 1972.

7) Narita, N. : Fundamental Investigation on Wind Resistance Design of Cable-Stayed Bridge with Solid Cross Section, Doctor Thesis Submitted to Univ. of Tokyo, 1978.

8) Kawashima, K. : A Computational Model of Friction Force in Dynamic Response Analysis, Proc. of Japan Society of Civil Engineers, Vol. 309, 1981.

9) Kawashima, K. and Penzien, J. : Correlative Investigation on Theoretical and Experimental Dynamic Behavior of A Model Bridge Structure, Report No. EERC 76-26, Earthquake Engineering Research Center, Univ. of California, Berkeley, 1976.

10) Bathe, K. J., Wilson, E. L. and Iding, R. H. : NONSAP-A Structural Analysis Computer Program for Static and Dynamic Response of Nonlinear System, Report No. UC SESM 74-3, Structural Engineering Laboratory, Univ. of California, Berkeley, 1974 .

11) Wilson, E. L., Farhoomand, I. and Bathe, K. J. : Nonlinear Dynamic Analysis of Complex Structures, International Journal of Earthquake Engineering and Structural Dynamics, Vol. 1, pp. 241-252, 1973.

12) Lazan, B. J. : Damping of Materials and Members in Structural Mechanics, Pergamon, 1968.

13) Iwasaki, T., Kawashima, K. and Unjoh, S. : Damping Characteristics of Cable-Stayed Bridges, Proceeding of the Third U. S. -Japan Bridge Workshop, pp. 137-151, 1987. 